\title{
A integração da educação profissional técnica de nível médio à educação de jovens e adultos: $o$ trabalho docente no proeja
}

\section{Telma Alves}

Instituto Federal de Educação, Ciência e Tecnologia do Rio de Janeiro tel.alv@gmail.com

\section{Maria Cecilia Fantinato}

Universidade Federal Fluminense

mcfantinato@gmail.com

\begin{abstract}
Resumo
Este trabalho apresenta uma investigação, em andamento, que tem como objeto o trabalho docente de professores que atuaram no curso técnico de Manutenção e Suporte em Informática que atende ao Programa Nacional de Integração da Educação Profissional com a Educação Básica, na modalidade de Educação de Jovens e Adultos (PROEJA) do Instituto Federal de Educação, Ciência e Tecnologia do Rio de Janeiro - Campus Rio de Janeiro. O PROEJA é um programa que aproxima a Educação Profissional (EP) da Educação de Jovens e Adultos (EJA). A pesquisa, de abordagem qualitativa, busca compreender como os professores enfrentaram desafios e especificidades próprios da complexidade oriunda da articulação destas duas modalidades de ensino. As entrevistas aprofundadas, concedidas pelos sujeitos da pesquisa, vão compor o material empírico que possibilitará reflexões sobre a construção/mobilização de saberes e fazeres desses professores. Após dez anos de implantação do PROEJA, a integração EP e EJA ainda é um desafio.
\end{abstract}

Palavras-chave: Educação de Jovens e Adultos. Educação Profissional. Saberes Docentes.

\section{The integration of high school level technical professional education with youth and adult education: the teaching practice in proeja}

\begin{abstract}
This work presents an ongoing research whose object is the teaching practice of teachers who worked in the technical course of Maintenance and Support in Computer Science that attends the National Program of Integration of Professional Education with Basic Education, in the modality of Youth and Adult Education (PROEJA) of the Federal Institute of Education, Science and Technology of Rio de Janeiro. PROEJA is a program that approximates the Professional Education (PE) of Youth and Adult Education (EJA). The research, with a qualitative approach, seeks to understand how teachers faced challenges and specificities inherent to the complexity arising from the articulation of these two teaching modalities. The in-depth interviews given by the research subjects will compose the empirical material that will enable reflections on the construction/mobilization of the knowledge and actions of these teachers. After ten years of PROEJA implementation, PE and EJA integration is still a challenge.
\end{abstract}

Keywords: Youth and Adult Education. Professional Education. PROEJA. Teachers`knowledge. 


\section{Introdução}

A Lei de Diretrizes e Bases da Educação Nacional - LDB - n 9394, de dezembro de 1996, trata da Educação de Jovens e Adultos (EJA) na Seção V, do capítulo II, e da Educação Profissional (EP) no capítulo III. Para a EJA, o parágrafo $1^{\circ}$ do artigo 37 assegura oportunidades educacionais apropriadas, consideradas as características específicas dos jovens e adultos que não puderam realizar, por razões diversas, a escolarização na idade própria. Para a EP, o inciso II, no parágrafo $2^{\circ}$ do artigo 39, afirma que a educação profissional abrangerá, entre outros, os cursos de educação profissional técnica de nível médio.

O Programa Nacional de Integração da Educação Profissional com a Educação Básica na modalidade de Educação de Jovens e Adultos (PROEJA) instituído pelo Decreto nº 5840/06, de 13 de julho de 2006, aproxima as modalidades EJA e EP. Ambas as modalidades tiveram trajetórias distintas ao longo da história da política educacional brasileira: a primeira foi, por muito tempo, foco de ações no sentido de compensar a falta de acesso à leitura e à escrita, como bens sociais, e a segunda, entendida como "treinamento eficiente da mão de obra necessária ao atendimento do projeto capitalista" (MACHADO, 2009, p. 27).

O PROEJA visa à integração da Educação Profissional com o Ensino Fundamental e com o Ensino Médio. Para atender ao PROEJA, em 2006, o Instituto Federal de Educação, Ciência e Tecnologia do Rio de Janeiro (IFRJ), na época CEFETEQ-RJ, implantou, nas unidades Nilópolis e Rio de Janeiro o curso de Manutenção de Suporte e Informática que doravante, neste texto, será denominado PROEJA/MSI. Esta pesquisa trata do ensino profissional articulado com o Ensino Médio, no local que hoje se denomina Campus Rio de Janeiro.

Nosso envolvimento com o PROEJA/MSI teve início em 2010. À época, encontramos um quadro de desmotivação dos alunos, do terceiro ao quinto períodos, causado pela falta de aulas de algumas disciplinas. Nossa experiência anterior, na modalidade EJA do ensino fundamental, nos permite afirmar como são importantes as reuniões semanais para o trabalho de equipe. O curso PROEJA/MSI tem previsão de encontros semanais, porém esses encontros, ao longo do tempo, vêm perdendo a periodicidade semanal, por vários motivos. Dentre os quais, podemos citar o fato de que alguns professores, por ministrarem aulas em outros cursos, no mesmo horário, não podem participar das discussões pedagógicas. Passamos a nos interrogar sobre as consequências dessa impossibilidade no trabalho docente.

A experiência anterior, de dois anos, no PROEJA do Colégio Pedro II (CPII), nos despertou expectativas, em relação ao PROEJA/MSI, devido à história de excelência do IFRJ, cuja gênese é a Escola Federal de Química - ETFQ, na modalidade de ensino profissional. Nos anos de implantação do PROEJA, 2006-2007, enquanto no CPII não havia sido realizada nenhuma reunião 
com o corpo docente para tratar dos objetivos do programa ou da reflexão sobre o currículo integrado, o PROEJA/MSI foi implantado, no IFRJ, após reuniões, discussões e envolvimento dos profissionais de diversas áreas.

À medida que nosso envolvimento crescia no curso PROEJA/MSI ${ }^{1}$, fomos aprofundando o conhecimento das dimensões institucionais e os limites que as mesmas impunham. Foi possível perceber a complexidade do trabalho docente a partir dos conselhos de classe e dos projetos desenvolvidos de acordo com o projeto político pedagógico do curso. Toda esta vivência nos levou ao estudo dos documentos legais.

O Documento Base do PROEJA, no sentido de caracterizar a forma integrada de oferta do curso, trata do currículo integrado e sobre este nos diz que "o que se pretende é uma integração epistemológica, de conteúdos, de metodologias e de práticas educativas” (BRASIL, 2007, p. 41). Assim, o currículo integrado visa a uma formação fundamentada na "integração de trabalho, ciência, técnica, tecnologia, humanismo e cultura geral" (BRASIL, 2007, p. 35).

O projeto político pedagógico do curso PROEJA/MSI do IFRJ está fundamentado na pedagogia de projetos e nos diz que

a proposta é trabalhar com a construção de conhecimentos significativos e deve estar contemplada em projetos interdisciplinares, que podem ser adotados como atividades inovadoras, eficazes e eficientes para o processo de ensino e aprendizagem (BRASIL, 2007, p.7).

À vivência da dimensão institucional acrescentamos o conhecimento das concepções políticas e pedagógicas, e passamos, então, a nos questionar acerca dos impactos dessas concepções e da própria instituição sobre a tarefa docente.

Inicialmente, nosso olhar se deteve no trabalho docente dos professores de Matemática que atuaram no curso, no período de 2006 a 2015. Porém, no processo de investigação, percebemos que a interdisciplinaridade, que fundamenta a proposta pedagógica do curso, nos demanda um olhar mais amplo. Além disso, a forma como é proposta a aproximação da EP à EJA pelo Documento Base do PROEJA nos instiga questões que não se restringem à Matemática. Por conseguinte, ampliamos nossa amostra de professores de forma a abranger a área de Ciências e Matemática e a área de Informática - técnica - do curso. Questões sobre como os professores compreendiam as modalidades de ensino de jovens e adultos e de ensino profissional, de que forma desenvolviam a tarefa docente ou em quais concepções apoiavam sua prática também nos despertaram para a importância da realização deste trabalho: a investigação, teórica e empírica, do trabalho docente dos professores que atuaram, no PROEJA/MSI do Campus Rio de Janeiro, no período de 2006 a 2016.

\footnotetext{
${ }^{1}$ A primeira autora deste trabalho exerceu, de 2011 a 2015, a função de coordenadora do curso PROEJA/MSI no Campus Rio de Janeiro do IFRJ.
} 
Em torno do problema de ensinar conteúdos das disciplinas da área de Ciência e Matemática e das disciplinas de formação técnica, num programa que aproxima as modalidades de ensino EP e EJA, podemos apresentar algumas questões. Qual a concepção de EJA que os professores assumem no seu trabalho docente? Como os professores compreendem o PROEJA? Quais saberes são necessários à prática pedagógica na EJA? Como os professores elaboram e reelaboram fazeres através de sua experiência docente no PROEJA? Essas são apenas algumas das questões que permeiam o trabalho docente no PROEJA. A escolha da questão principal recaiu sobre como os professores utilizaram/construíram saberes e fazeres no seu trabalho docente de ensinar conteúdos aos jovens e adultos, na educação profissional técnica de nível médio. O estudo para responder à pergunta tem, então, o objetivo de compreender desafios e especificidades do trabalho docente no curso PROEJA/MSI, do Campus Rio de Janeiro.

No desenvolvimento do texto relataremos algumas das reflexões teóricas realizadas até o presente momento e a metodologia eleita para atingir os objetivos. Em seguida, o registro sobre a primeira aproximação, realizada na fase exploratória com um dos professores, revela uma pequena amostra da riqueza do material a ser coletado, analisado e interpretado. As considerações, ao final, são provisórias e representam uma breve síntese dos dois anos de estudos empreendidos. Podemos vislumbrar que o registro da narrativa dos professores, em confronto com outras fontes, possivelmente, nos dará suporte para realizar uma análise crítica do trabalho docente no PROEJA, no sentido de contribuir para a formação docente inicial e continuada.

\section{Reflexões à luz de alguns referenciais}

Gauthier (2013), Tardif (2012) e Shulman (1986) são autores com os quais procuramos dialogar, antes da etapa da pesquisa de campo. Gauthier (2013) trata do problema de ser possível caracterizar a natureza dos saberes que permeiam o ato de ensinar. Essa possibilidade nos parece muito promissora no caso desta investigação, uma vez que a formação inicial e continuada para a EP integrada à EJA ainda parece incipiente.

Tardif (2012, p. 255) nos apresenta a proposta de uma epistemologia da prática profissional como o estudo do "conjunto de saberes utilizado realmente pelos profissionais em seu espaço de trabalho cotidiano para desempenhar todas as suas tarefas", cuja finalidade é compreender como esses saberes se integram ao trabalho dos profissionais e como os mesmos os agregam, os produzem, os mobilizam e os modificam.

Shulman (1986) nos mostra seu entendimento do saber pedagógico-disciplinar como uma estreita articulação entre o domínio do conteúdo e a forma de ensiná-lo. Aproximando as ideias de Shulman (1986) da tarefa de ensinar na EJA, percebemos a importância do papel do professor, 
como detentor do conhecimento do conteúdo, por ter a responsabilidade de mostrar o que é essencial e o que é secundário. Segundo Almeida e Biajone (2007) é importante que o professor recorra às diversas compreensões que tem do conteúdo para oferecer explicações alternativas dos mesmos conceitos e princípios. No caso da EJA, essa ideia se mostra pertinente, já que uma de suas características é a diversidade de seus alunos.

Tardif (2012) nos diz que os saberes, como esquemas, regras, hábitos, procedimentos, tipos, categorias etc. não são inatos. Isso significa que é "através do processo de imersão dos indivíduos nos diversos mundos socializados (famílias, grupos, amigos, escolas, etc.), nos quais eles constroem, em interação com os outros, sua identidade pessoal e social” (TARDIF, 2012, p. 71).

Ao dialogarmos com esses autores, podemos considerar que os professores do IFRJ, que atuam em diferentes níveis de ensino - médio e superior - e com diferentes estudantes - os que estão na idade própria ${ }^{2}$ e os que estão na EJA - exercem seu trabalho docente nesses diferentes contextos de ação, apoiados em saberes diversos. Assumimos, então, que a investigação toma foco na pluralidade e heterogeneidade dos saberes e nas suas diversas origens. A intenção da pesquisa é a de compreender desafios e especificidades do trabalho docente, focando na produção e mobilização de saberes oriundos de diversas fontes.

Investigar como os professores da área de Ciências e Matemática realizam suas tarefas docentes no ensino profissional técnico de nível médio, na modalidade EJA, nos coloca a necessidade de dialogar com a produção da área. Nesse sentido, encontramos em Krasilchik (2000) um panorama das mudanças ocorridas no ensino das Ciências. O reconhecimento da importância da Ciência e da Tecnologia para o desenvolvimento econômico, cultural e social foi elemento importante para mudanças. Essa mesma autora nos diz que modalidades didáticas para o ensino das disciplinas científicas estão em relação direta com a concepção assumida de aprendizagem da Ciência.

O Projeto Político Pedagógico do PROEJA/MSI do IFRJ assume explicitamente a concepção de aprendizagem significativa, na qual o professor é um mediador do conhecimento do aluno e dos novos conceitos, afirmando que, por essa concepção, “a aprendizagem pelo aluno não foi construída de forma mecânica, mas a partir daquilo que tem significado para ele e que está próximo da sua realidade" (BRASIL, 2007, p.8). A proposta pedagógica de trabalhar com a construção de conhecimentos significativos, a nosso ver, traz o mesmo problema que Krasilchik (2000) evidencia em seu texto: a distância entre a proposta construtivista e as "recomendações que permitam ao professor exercer plenamente o seu papel de catalisador da aprendizagem" (KRASILCHIK, 2000, p. 88). Nesse sentido, será pertinente investigar, na etapa do trabalho de

\footnotetext{
${ }^{2}$ Termo usado no artigo 37 da LDB 9394/96 para designar aqueles que têm acesso aos ensinos fundamental e médio sem a distorção idade/ano escolar.
} 
campo, se há ausência de discussões que permitam ao próprio docente, em suas condições de trabalho, criar um clima de liberdade intelectual, que não limite sua atividade a exposições orais.

Encontramos, mais especificamente, sobre o ensino de Física no Ensino Médio, no trabalho de Monteiro, Nardi e Filho (2009) relatos de professores sobre dificuldades relativas ao ensino estarem associadas à formação inicial. Isso porque alguns professores, de Física, atribuem à área pedagógica a função de apresentar técnicas para o ensino de determinado conteúdo, como se estratégias de ensino fossem uma técnica.

Talvez a formação dos professores de Física ainda esteja, como nos dizem Cyrino (2006) e Paiva $(2002$; 2006) em relação à formação da maioria dos professores de Matemática, centrada no paradigma da racionalidade técnica ${ }^{3}$. Identificamos em ambas as autoras reflexões que problematizam essa perspectiva, bem como visam superá-la.

Cyrino (2006) propõe o debate sobre as concepções acerca do conhecimento matemático e do seu ensino, afirmando que compreender a dinâmica dessas concepções, sua origem e como suas transformações ocorrem, pode indicar os fatores que levam os alunos a decidir se tornarem professores. O que vem ao encontro de Tardif (2012), quando afirma que conhecer a razão pela qual o professor escolhe a profissão pode nos dizer muito sobre a forma como desenvolve seu trabalho. Já Paiva (2006) busca a superação desse paradigma, ao discutir a identidade profissional do professor, recorrendo à ideia de que ele detém a tarefa de "tornar a obra matemática apta a ser trabalhada no contexto escolar" (PAIVA, 2006, p. 91). Nesse sentido, o professor não é um mero executor do que é prescrito pelas universidades, mas um profissional que constrói, em seu trabalho docente, saberes que irão conduzir suas ações em sala de aula. Essas são algumas das ideias que trazemos para embasar a investigação sobre o trabalho dos professores no contexto da EP integrada à EJA.

Em relação à Educação Matemática de Jovens e Adultos, Fonseca (2002) nos chama atenção para a relevância social do conhecimento matemático, para a responsabilidade das escolhas pedagógicas que evidenciem essa relevância no ensino de Matemática e a "flexibilização nas exigências de padronização na expressão dos procedimentos matemáticos” (FONSECA, 2002, p.79). A autora destaca, ainda, que o público da EJA pertence a um grupo sociocultural para o qual a escola não foi, por tradição, direcionada e, dessa forma, devemos procurar olhar para esse público como "sujeitos culturais: nos quais se reconhecem as marcas da cultura permeando [...] intenções e modos do seu fazer e do seu estar no mundo, e, portanto, de suas motivações e recursos de matematizar" (FONSECA, 2002, p. 80). Nesse sentido, as pesquisas em Etnomatemática têm se

\footnotetext{
${ }^{3} \mathrm{O}$ paradigma da racionalidade técnica é uma concepção epistemológica da prática, herdada do positivismo, na qual a atividade profissional é instrumental, dirigida para a solução de problemas mediante a aplicação rigorosa de teorias e técnicas científicas (PÉREZ GÓMEZ, 1995, apud CYRINO, 2006).
} 
mostrado bastante férteis no campo da educação de jovens e adultos tanto por expressarem esse reconhecimento do sujeito cultural, quanto por apontarem possibilidades para a formação inicial de professores de Matemática.

\section{Metodologia}

Para realizar as análises das questões e atender os objetivos propostos, entendemos que a abordagem qualitativa é a que está em adequação com o foco da pesquisa, por este ser mais amplo e partir de uma perspectiva diferenciada. Pretendemos entender a complexidade da tarefa de ensinar as disciplinas da área de Ciências e Matemática e da área técnica - Informática - no PROEJA/MSI, a partir da perspectiva dos próprios sujeitos professores. Percebemos cada sujeito da investigação como um indivíduo que tem suas experiências pessoais, profissionais, sua formação préprofissional, que são elementos que compõem o profissional que exerce sua tarefa. Sob esse olhar, a investigação, que visa compreender as percepções dos professores sobre seu trabalho, terá como fonte principal a narrativa dos profissionais que trazem, para seu contexto profissional, suas disposições, sua maneira de ser professor e de realizar suas tarefas profissionais.

Bogdan e Biklen (1994) sinalizam como um elemento central, que caracteriza a pesquisa qualitativa, o fato de o pesquisador se interessar pela importância do significado que os participantes da pesquisa conferem às suas trajetórias e aos seus fazeres. Pretendemos que a investigação exponha o dinamismo interno - que ainda parece imperceptível ao observador externo - do trabalho docente pela narrativa das crenças, valores, interesses, concepções diversas e dificuldades dos professores. Não esquecendo que Lüdke e André (2013) nos alertam para o cuidado que o pesquisador deve ter ao interpretar o que lhes dizem os participantes.

A investigação assume contornos de um estudo de caso, pois busca apresentar as múltiplas dimensões que envolvem o trabalho docente dos professores das áreas de Ciências e Matemática e técnica, no PROEJA/MSI, ressaltando os detalhes e as circunstâncias específicas que ajudam a compreender essa unidade como um todo. Nesse sentido, o conhecimento sobre a forma como, ao longo desses dez anos de existência do PROEJA/MSI, os professores foram indicados para ensinar no curso, a opção pela pedagogia de projetos para materializar o currículo integrado - da qual, percebemos muitas vezes, que boa parte de tais professores permanecem distantes - e as especificidades das duas modalidades - EP e EJA - são pontos críticos que foram sendo explicitados à medida que a fase exploratória se desenvolveu.

O material empírico será obtido através de entrevistas aprofundadas, realizadas a partir de fevereiro de 2017, nos apoiando em Kaufmann (2013), que nos apresenta uma proposta 
metodológica que é particular e que envolve técnicas de pesquisa qualitativa e empírica, com destaque para técnicas etnológicas de trabalho com informantes.

Em DaMatta (1978), a Etnologia apresenta uma fase ${ }^{4}$ denominada teórico-intelectual determinada pela separação entre o futuro pesquisador e o grupo que se busca ver, encarar, perceber, estudar, interpretar, explicar. Segundo esse autor, essa separação se dá pelo excesso de conhecimento teórico, universal e mediado pelo abstrato e não vivenciado (DaMATTA, 1978). E esse é um desafio que devemos enfrentar durante a investigação empírica, na medida em que podemos encontrar/ter muitas elaborações sobre os professores em contextos de educação de jovens e adultos e educação profissional, mas apenas os próprios professores que atuaram no PROEJA/MSI do Campus Rio de Janeiro podem nos informar como vivenciaram essa experiência. É nesse aspecto que a entrevista compreensiva (KAUFMANN, 2013) se adequa ao objeto da pesquisa, já que os dados qualitativos coletados, no seu lugar natural, estão na palavra recolhida que se torna o elemento central. Por esse método, esperamos captar dos professores da área de Ciências e Matemática e da área técnica do PROEJA/MSI os significados que oferecem ao objeto da pesquisa - o próprio trabalho docente - inserido num contexto dinâmico (escola pública) com atores (professores) que não são feitos de uma só faceta (a profissional), mas de complexos matizados de disposições para agir e para crer.

\section{A Primeira aproximação - na fase exploratória}

Na fase exploratória, realizada em janeiro de 2014, o professor de Matemática - agora aposentado que atuou no segundo semestre de 2006, época da implantação do curso técnico integrado PROEJA /MSI, no Campus Rio de Janeiro, narrou suas experiências de vida, na escola e na graduação, como também a sua opção pelo ensino da Matemática.

Foi possível, nessa primeira aproximação, perceber características particulares desse professor, como sua desistência do curso de engenharia por não ter gostado de trabalhar em usinas. Este professor relatou que, para ganhar sustento, recorreu a ministrar aulas particulares. Nessa atividade experimentou a alegria de ver "os olhos, de uma moça, brilharem" (Entrevista concedida em 23 de janeiro de 2014) ao entender um determinado conteúdo. O professor deu destaque não só à emoção da estudante, mas também à sua própria emoção. E foi nesse momento que se decidiu pela profissão de ensinar. Tardif (2012) considera que a razão da escolha pelo magistério é um componente que influencia o fazer pedagógico do professor.

\footnotetext{
${ }^{4}$ Segundo DaMatta são três as fases da Etnologia: a inicial denominada teórico-intelectual, a segunda que é o período prático e a fase final que ele chama de existencial.
} 
Esse mesmo professor, ao relatar uma prática pedagógica, no PROEJA, de relacionar os números e as operações matemáticas com as contas de luz residenciais, demonstra sua preocupação de não excluir da atividade, aqueles estudantes que, por ventura, moravam em comunidades desprovidas deste tipo de serviço. Ele, na adolescência, conviveu com amigos (na vizinhança) e colegas (na escola) que experimentavam situações de precariedade social como as que seus alunos relatavam. Sua trajetória social foi fonte para a construção de um fazer na prática pedagógica. Esse é um exemplo das muitas situações, em sala de aula, que desafiam o modelo da racionalidade técnica. A diversidade presente numa sala de aula da modalidade EJA exige do professor um saberfazer durante o desenvolvimento da aula que, muitas vezes, pode ter relação com a socialização préprofissional do professor.

Esse professor, entrevistado na fase exploratória, não olha para os alunos pelo o que lhes falta, mas, segundo seu entendimento, admite que exista a necessidade de compensar o atraso educacional de que foram vítimas os jovens e adultos trabalhadores, principalmente se o Brasil quiser avançar nas suas conquistas sociais. Ele afirma que a educação profissional integrada ao ensino médio ainda é um estudo de caso e que considera o PROEJA um projeto voluntarista, na medida em que é feito da vontade política de alguns em abraçar uma causa.

Compreendemos sua postura como dialética, uma vez que aponta para a contradição entre a complexidade do programa e a ausência de aporte teórico para sua implantação. Tais constatações encontram respaldo nos estudos de Ventura e Rummert (2015) e Ciavatta e Rummert (2010). As primeiras apontam para a falta de enfrentamento às questões teóricas no processo de formação docente e as últimas para as dificuldades no processo de construção do currículo integrado.

\section{Considerações Finais}

Uma conclusão provisória se refere à possibilidade de que a EJA, a partir do momento em que passa a ser considerada como um direito garantido pela Constituição Federal de 1988, assim como uma modalidade da Educação Básica, tenha se tornado um problema para o ensino da área de Ciências e Matemática, na medida em que os professores ainda são formados na perspectiva da racionalidade técnica, na qual a atividade docente é exercida pela aplicação de um conjunto de técnicas.

Nos últimos vinte anos, podemos perceber uma dinâmica intensa na superação de preconceitos e estigmas históricos que marcam a EJA e na construção do conceito de uma educação para toda a vida, mas parece que esse movimento chega, ainda, de forma muito lenta aos espaços de formação e ao interior das instituições.

O programa PROEJA é conceitualmente difícil porque envolve as questões da integração da educação básica à educação profissional, assim como a da especificidade da modalidade da 
educação de jovens e adultos. A primeira envolve o conceito de currículo integrado e a segunda envolve o modo próprio de ensino aos adultos com suas experiências de vida. Outro aspecto se refere ao fato de, apesar de esse programa ter sido proposto e implantado dez anos após a promulgação da LDB n 9394, os cursos de formação inicial de professores da área de Ciência e Matemática se mantêm fundamentados no modelo da solução de problemas mediante a aplicação rigorosa de teorias e técnicas científicas, o qual pode não atender aos objetivos dessa política. As modalidades de educação de jovens e adultos e educação profissional exigem daqueles que formulam políticas públicas, programas ou projetos para essas modalidades, a preocupação com a formação inicial e continuada no sentido de diminuir a distância entre o que é proposto e o que acontece no processo de aplicação da proposta.

A definição oficial dos princípios que vão orientar as ações curriculares é importante, mas é o trabalho do professor que pode fazer a mediação entre o currículo oficial e as condições objetivas dadas pelo contexto escolar. Nesse sentido, este estudo tem foco na narrativa que cada professor irá realizar sobre suas ações, explicitando a própria compreensão dos conhecimentos que detém e a importância que atribui a transmiti-los a jovens e adultos. A expectativa é trazer à tona os desafios derivados do processo pedagógico que desenvolveram no PROEJA/MSI, e poder contribuir para tornar claros os objetivos do ensino da área de Ciência e Matemática na educação profissional técnica de nível médio, na modalidade de educação de jovens e adultos. Nos últimos dez anos muitos trabalhos acadêmicos foram produzidos tendo como campo empírico o PROEJA; no entanto, há poucas referências à forma como utilizam/constroem os saberes/fazeres dos professores, das áreas de Ciência e Matemática e da área técnica, quando atuam nesse programa. A importância desse trabalho encontra-se na proposta de explicitar os desafios e as especificidades do trabalho dos professores, tornando-os visíveis e passíveis de socialização, com o objetivo de aprofundar a problematização da profissão docente e aproximar a prática da formação inicial dos professores dessas áreas.

\section{Referências}

ALMEIDA, P. C. A. de; BIAJONE, J. Saberes docentes e Formação inicial de Professores: implicações e desafios como propostas de Formação. Educ. Pesqui. São Paulo, v. 33, n. 2, agosto, 2007, p. 281-295. Disponível em <http://www.scielo.br/scielo.php?script=sci_arttext\&pid=S1517$97022007000200007 \& \operatorname{lng}=\mathrm{en} \& n r m=$ iso $>$. Acesso em 02/01/2016.

BOGDAN, R. C.; BIKLEN, S. K. Investigação Qualitativa em Educação. Porto, Portugal: Porto Editora, 1994.

BORGES, C.; TARDIF, M. Apresentação. Educação \& Sociedade. São Paulo, Ano 22, n. 74, abr. 2001. 
BRASIL. Lei de Diretrizes e Bases da Educação Nacional, n. 9.394: promulgada em 20 de dezembro de 1996. Disponível em: <www.mec.gov.br/legis/default.shtm>. Acesso em 07/02/ 2016.

BRASIL. MEC/SETEC. Ministério da Educação. Secretaria de Educação Profissional e Tecnológica. Documento Base. PROEJA. Programa Nacional de Integração da Educação Profissional com a Educação Básica na Modalidade de Educação de Jovens e Adultos. Brasília, ago. 2007.

BRASIL. CEFETEQ/RJ. Diretoria de Ensino Médio Técnico. Projeto Político Pedagógico do Curso PROEJA/MSI. Nilópolis, jul. 2007.

CYRINO, M.C. de C. T. Preparação e emancipação profissional na formação inicial do professor de Matemática. In: NACARATO, A.D.; PAIVA, M; A. V. (Orgs.) A Formação do professor que ensina Matemática: perspectivas e pesquisas. Belo Horizonte: Autêntica, 2006, p. 77-88.

DAMATTA, R. O Ofício do Etnólogo, ou como Ter “Anthropological Blues” In: NUNES, E. de O. (Org.) A aventura sociológica. Rio de Janeiro: Zahar Editora, 1978, p. 23-35.

FONSECA, M. C. F. R. Educação Matemática de jovens e adultos. Belo Horizonte: Autêntica, 2002.

GAUTHIER, C. et al. Por uma teoria da pedagogia: pesquisas sobre o saber docente. 3. ed. Ijuí: Ed. Unijuí, 2013. (Coleção Fronteiras da Educação)

GOODSON, I. F. Dar Voz ao Professor: As Histórias de Vida dos Professores e o seu Desenvolvimento Profissional. In: NÓVOA, A. (Org.). Vida de Professores. Porto, Portugal: Editora Porto, 2007, p. 63-78. (Coleção Ciências da Educação).

KAUFMANN, J. C. A Entrevista Compreensiva: um guia para pesquisa de campo. Tradução de Thiago de Abreu e Lima Florencio; revisão técnica de Bruno César Cavalcanti. Petrópolis, RJ: Vozes; Maceió, AL: Edufal, 2013.

KRASILCHIK, M. Reformas e realidade: o caso do ensino das ciências. São Paulo Perspec. São Paulo, v. 14, n. 1, p. 85-93, 2000.

LAHIRE, B. Entrevista com Bernard Lahire. Áskesis - Revista dos Discentes do PPGS/UFSCar, São Carlos, v. 1, n. 1, p. 200-210, 2012.

LAHIRE, B. Patrimônios individuais de disposições - Para uma sociologia à escala individual. Sociologia, Problemas e Práticas, Oeiras, n.49, p. 11-42, 2005.

LAHIRE, B. Trajetória acadêmica e pensamento sociológico. Entrevista à Educ. Pesqui., São Paulo, v. 30, n.2, p. 315-321, 2004

MACHADO, M. M. A educação de jovens e adultos no Brasil pós-Lei n ${ }^{\circ}$ 9.394/96: a possibilidade de constituir-se como política pública. In: MACHADO, M. M. (Org.). Educação de Jovens e Adultos. Brasília: INEP, 2009.

MONTEIRO, M.A.; NARDI, R.; FILHO, J.B.B. Dificuldade dos Professores em Introduzir a Física Moderna no Ensino Médio: a necessidade de superação da racionalidade técnica nos processos de formativos. In: NARDI, R (Org.). Ensino de ciências e matemática, I: temas sobre a formação de professores. São Paulo: Cultura Acadêmica, 2009, p 145-159.

NÓVOA, A. Apresentação. In: NÓVOA, A. (Org.). Vida de Professores. Coleção Ciências da Educação. Porto, Portugal: Editora Porto, 2007.

Os professores: Um "novo" objeto da investigação educacional? In: (Org.). Vida de Professores. Coleção Ciências da Educação. Porto, Portugal: Editora Porto, 2007, p. 14-30. 
PAIVA, M.A.V. O Professor de Matemática e sua formação: a busca da identidade profissional. In: NACARATO, A.D.; PAIVA, M; A. V. (Orgs.) A Formação do professor que ensina

Matemática: perspectivas e pesquisas. Belo Horizonte: Autêntica, 2006, p. 89-110.

. Saberes do Professor de Matemática: uma reflexão sobre Licenciatura. In: Educação

Matemática em Revista - Licenciatura em Matemática um curso em discussão. São Paulo: SBEM, ano 9, no 11, p. 95-104, abr. de 2002.

POUBEL, C.M.S.; PINHO, L.G. Política Educacional e Proeja: Um Balanço das Produções Acadêmicas Entre Os Anos De 2009 Até 2013. In: Entrelaçando olhares por uma educação planetária: anais completos: 2. Seminário de Jovens e Adultos da PUC - Rio/ (Orgs.) Renato Pontes Costa e Valéria Mendonça Vianna. 1. ed. - Rio de Janeiro: Caetés, 2015, p.303-313.

TARDIF, M. Saberes docentes e Formação Profissional. 14 ${ }^{\text {a }}$ Ed. - Petrópolis, RJ: Vozes, 2012.

Submetido em janeiro de 2017 Aprovado em março de 2017 